\title{
The Process of Stigmatization as a Desocializing Factor
}

\author{
Svetlana Turkulets \\ Department of Criminal Law \\ Disciplines \\ Far Eastern State Transport \\ University \\ Khabarovsk, Russia \\ turswet@rambler.ru
}

\author{
Aleksei Turkuletc \\ Department of Criminal Law \\ Disciplines \\ Far Eastern State Transport \\ University \\ Khabarovsk, Russia \\ tual63@mail.ru
}

Svetlana Dimitrova

Department of Philosophy

Volgograd State University

Volgograd, Russia

sve-dimitrova@yandex.ru

\author{
Evgenia Listopadova \\ Department of Criminal Law \\ Disciplines \\ Far Eastern State Transport \\ University \\ Khabarovsk, Russia \\ ugpd@rambler.ru
}

Nina Anikeeva

Department of Philosophy, Sociology and Law

Far Eastern State Transport University

Khabarovsk, Russia ugpd@rambler.ru

\author{
Ruslan Bazhenov \\ Department of Information \\ Systems, Mathematics and Law \\ Informatics \\ Sholom-Aleichem Priamursky \\ State University \\ Birobidzhan, Russia \\ r-i-bazhenov@yandex.ru
}

\begin{abstract}
Based on the analysis of the theory of symbolic interactionism and publications of modern scientists, representing various scientific directions of social and humanitarian knowledge, the article actualizes the point of view according to which the processes of social stigmatization are desocializing. The purpose of the article is to justify the ambivalence of the forms of a social identity process, the essence of which is most clearly manifested in the discrepancy between real and virtual identity. A person is in a situation of direct or indirect contradiction between his inner experience of his belonging to the corresponding social group, on the one hand, and the evaluation of his place and role made by other participants of social interactions, on the other. Using comparative methodology, the authors define the main criteria for comprehending and evaluating stigmatization processes. The article asserts the idea that symbolic interactionism, in fact, is a practical sociological tool that does not pretend to identify general tendencies and patterns.
\end{abstract}

Keywords - socialization, social identity, stigmatization, adaptation, symbolic interactionism.

\section{INTRODUCTION}

Modern social world is characterized by extreme variability, rapid transformation of values, and large-scale civilizational challenges. This situation causes a split in the internal spiritual orientations of the individual, cognitive dissonance regarding the evaluation of one's own place and role in a rapidly changing world. Traditional mechanisms of socialization, understood as a process of learning skills of social interaction and cultural adaptation, are currently ineffective and do not bring expected results. In addition, this situation initiates the activity of factors opposing normal socialization of individuals. In this regard, the problem of adequate self-determination of an individual becomes extremely relevant. It should be noted that social identity of an individual is one of the key topics of social and human sciences; research works of many modern scientists focus on its description.

The overall objective of this work is the analysis of stigmatization processes in the context of determining the essence of social identification of a contemporary person on the basis of social and humanitarian studies. The purpose of the article is to justify the ambivalence of forms of a social identity process, the essence of which is most clearly manifested in discrepancy between real and virtual identity.

Let us turn to the ideas of symbolic interactionism, which arose as an alternative to structural functionalism, a very common and influential trend in American sociology in the second half of the 20th century. While the supporters of structural-functional analysis (T. Parsons, R. Merton) positioned themselves as "theorists with a capital letter" seeking to create an objective sociological theory of macrolevel, the advocates of symbolic interactionism (C. Cooley, D. Mead, G. Bloomer, G. Becker, E. Goffman) considered their task to describe the immediate social reality, which, from their point of view, in turn, is the product of role interactions between people.

From the point of view of symbolic interactionism, social life is a constatntly reproduced interaction between constructively acting individuals, meeting in the context of certain specific situations. Society itself was considered by the ancestors of this approach, as a sum of self-sufficient interpersonal communications and interactions between "I" and "You", "I" and "Others". Representatives of this approach assumed self-consciousness and value orientation of a person "mirror" the reactions to it from people around them. It followed that an individual perceives himself/herself indirectly, through other representatives of a social group an individual 
belongs to. It is the process of indirect cognitive and spiritual communication that forms a social group as a kind of integrity. The result of the development of this initial thesis was the theory of "mirror I" and a group theory (C. Cooley), a personality theory (D. Mead), and a social interaction theory (G. Bloomer).

\section{RESULTS}

One of the key concepts of the doctrine under consideration is deviation. It is asserted that deviation is a specific form of judgment about the actions of an individual on the part of various participants of social interaction, in the structure of which these actions are carried out. Deviation is not an individual property of a person, but a socially relational property. Deviation serves as a pointer, in other words, it highlights behavioral reactions unacceptable under the circumstances. This is a social "sticker" (or "label"). Thus, deviation is basically a necessary factor in the process of interaction of social groups which compete with each other in the nomination, substantiation and justification of certain social values. Competitiveness of social environment is the basis which provokes the phenomenon of deviation constantly.

Any person, regardless of occupation, political convictions, moral attitudes, is potentially a deviant because of necessary inclusion in the acts of social interaction. However, to turn deviant into reality, at least two conditions should be in place: 1. Existence of the so-called "entrepreneurs of morality" in a community (these are groups of the highest social status, some "moral impresarios", devoted servants of social virtues, "crusaders of the spirit", "moral reformers"); 2. Process of "moral labeling," or, in other words, stigmatization of individual social agents or groups as deviating from the norms, traditions, and values accepted in a community.

Deviation serves as a social building that ensures the unity and stability of a community through conscious or unconscious stigmatization of all social subjects not falling under generally accepted standards. It is the exclusion of deviants from the range of socially justified circumstances and conditions of existence that gives legal majority of a community the right to justify their own norms. It turns out that the community itself, voluntarily or not, provokes deviant behavior in the right amount and forms which are necessary to find the so-called "scapegoats" and punish them publically, thereby demonstrating the significance of established rules.

In the authors' opinion, the study of the so-called "deviant career" by the representatives of symbolic interactionism is very promising. This concept is used for analyzing the stages of the process of turning an individual into a deviant. It is considered that deviation is not a static property or a characteristic of a particular person, deviation is seen as a process. A person is not originally a deviant, but becomes one. Stages of deviant socialization are following:

- formless social environment (lack of income or social life resources, poor conditions in general, unemployment);

- primary identification of oneself with a certain marginal group (superficial assimilation of its norms);

transition from an isolated deviant act to the implementation of a series of similar violations (misconducts); at this stage, the habit of "being different" is developed;
- consolidating the deviant status through the symbolic ritual of "tying" to the deviant lifestyle, the process of stigmatization (labeling);

- preparation, training and usage of criminal technologies (for example, transition from drug consumption to drug trade);

- prestigious condemnation of criminal acts (accumulation of the deviant authority);

- acquiring a criminal identity in a "crime school" (prison); this is the stage when both internal transformation of a deviant's image (interiorization of criminal environment norms) and external attitude of a deviant towards legal social structures (guards, judges, lawyers, police, etc.) take place, which results in the respective behavior and speech (exteriorization of the internal autonomy);

- further intensification of social marking, which is reflected in prohibition of employment bypassing relevant institutions established specifically for this purpose; tougher punishment at relapse of criminality.

Note that standard mechanisms of social transformation of an individual work at every stage of a "deviant career". However, from the point of view of an external observer, the triviality of these mechanisms turns into an internal personal tragedy for each person involved in this process for one reason or another. It should be emphasized that the result of a "deviant career" is identification of a person as a deviant. And often this personal social and legal identity is perceived by a deviant himself as subjectively positive.

Symbolic interactionism approach might be developed in two directions, i.e. direct and reverse. Direct interpretation considers clarification and analysis of mechanisms of transition from the first stage to the latter, with the aim of developing effective measures to halt or even stop this process. The reverse interpretation addresses the problem of positive resocialization of a former deviant when the person, forced or by choice, returns to normal conditions of social existence after a long stay in socially traumatic abnormal situations. Of course, the process of positive resocialization is not a mirror copy of a "deviant career". Effective resocialization is only possible when an individual independently starts or at least tries to model new behaviors corresponding to generally accepted social standards, consistently and actively embodies them in his/her behavioral acts.

One of the most significant desocialisers is stigmatization. Modern researchers of stigmatization take up the most common grounds for "labeling" such as: 1. Non-standard appearance (overweight or obesity, mutilation); 2. Mental illnesses, drug / alcohol addiction, other types of diseases or disorders; 3. Different sexual orientation; 4. Criminal past; 5. Inconsistency with established stereotypes of a "successful person"; 6. Territory of residence, etc.

In order to comprehend the diversity of opinions, points of view and various procedures for describing the phenomenon of stigmatization that are presented in modern studies, it is necessary to apply a systematic approach that implies a clear definition of the following fixed criteria for analysis: historical, substrate, value, and functional.

Historical criterion allows determining the position of the author regarding solving the problem of origin, formation and prospects for the development of stigmatization procedures. In 
turn, substrate criterion makes it possible to determine the substance of these phenomena in a research work of one or another author. The value criterion is aimed at revealing wellfounded values that are explicitly or implicitly attributed by a particular author to the stigmatization process itself, or to individual components of the process. The functional criterion is aimed at revealing the position of the author in relation to the function which is, from the researcher's point of view, performed by the stigmatization process in the social environment where it is directly carried out.

These criteria, of course, are not the utmost possible tools for analyzing the experience of stigmatization in the modern science. They can serve only as a working tool in the future development of this subject.

\section{DISCUSSIONS}

Let us turn to modern research works, which provide analysis and assessment of stigmatization processes. We emphasize that the analyzed positions of scientists reflect the belonging to one of the above criteria for describing a stigmatization.

C. Sikorski, M. Luppa, M. C. Angermeyer, G. Schomerus, B. Link, S. G.Riedel-Heller [1] focused their research on elucidating the prevalence of the phenomenon of social distance towards people suffering from obesity, as well as the identification of emotional reactions of participants in social interactions to this phenomenon. Researchers came to the conclusion that emotional response of surrounding people, as a rule, was expressed in the following experiences: pity, sympathy, misunderstanding, uncertainty, joking. The authors believe that it is the change in the emotional responses of surrounding people to those who are obese (from lack of understanding to sympathy) that can be the starting point in activities aimed at overcoming social distance. This study expresses a value characteristic of the process of stigmatization.

Despite the fact that S. J. Mooney and A. M. El-Sayed [2] view the problem of stigmatization from different perspective, they also use the axiological principle. They analyze etiology of depression among obese people. According to the authors, stereotyped ideas of so-called "body norm", such as a model of beauty and health, play their role here. The more distant the real proportions of the body from these imposed by the society models are, the more dramatic and deep the depression might be. The authors note that depression is more common among obese people when their percentage to the total number of the so-called "normal people" is rather small. Significantly, the authors define the risk of depression among obese people as a function of the obesity rate imitating the average statistical indicators for the entire population. The authors argue that the social isolation (ostracism) of obese people only exacerbates their depression.

A number of studies are focused on the determinants of the "mental illness" stigma. In her research, N. Tuntiya [3] analyzes the process of social stigmatization by the example of people with severe chronic mental illnesses integrated into small communities. The author shows that these patients usually tend to reject the stigmatized "status of the patient" imposed on them by the external environment. Using data of several dozens of mentally ill patients, the author concludes that these people are not passive participants in the socialization process but rather functional members of the community in which they are needed. They make a certain contribution to the functioning of their group, influencing the structure and dynamics of intra-group interaction either explicitly or implicitly.

T. Moses [4] conducts a study among adolescents who have undergone psychiatric hospitalization. The key factors here are: group identification of adolescents themselves, their social origin, efficiency (or inefficiency) of the functioning of school programs for the rehabilitation of adolescents. Moreover, the following dependence is observed: the higher the social status of a stigmatized teenager and the lower the level of general development of the members of the group they belong to, the higher the risk of being stigmatized by a "mental illness". The researcher notes that the aspiration of teenagers who have undergone a course of psychiatric hospitalization to join a group where others like them ("making friends among peers") only increases the probability of being subjected to "mental illness" stigma from general school environment.

Japanese specialists M. Kayama and W. Haight [5] elaborate on the adolescent emotional reactions to the assessment of others. In their study, they draw on the experience of parents in assessing behavioral and cognitive disorders of their children in primary school. The authors note that general high sensitivity of the population to the threat of stigmatization due to certain individual characteristics is traditional for Japanese culture. Not only real but even imaginary (possible or expected) negative reaction of surrounding people often leads to social isolation. On the basis of the collected empirical material, the authors state that this particular feature is most acute in a childhood period, i.e. primary school age. A special role in overcoming this tradition is played by the experience of school teachers, employees, management staff, medical workers, who are called to help new generations in successful social adaptation together with their parents.

The content of the next study describes functional criterion of the reflection of stigmatization to a certain extent. H. J.Whittle, K. Palar, N. A. Ranadive, J. M.Turan, M. Kushel, S. D.Weiser [6] address the problem of stigmatization at the level of government bureaucracy system. It is about the mechanism for issuing disability benefits in the United States. Based on the data obtained as a result of the ongoing neoliberal reforms in the country's welfare, the authors come to the conclusion that the system itself, initially designed to help the destitute, provokes a process of negative stigmatization. Citizens who contact relevant support agencies are labeled as "disability fraudsters", "lying malingerers", "unworthy poor" and other desocial subjects. The data obtained as a result of the research show a complex picture of a real situation when inflexible and intricate bureaucratic management of a social security system for disabled people increasingly manifests its social disfunctionality. The authors believe that their research reflects real historical context of the ongoing neoliberal reforms.

Stigmatization based on belonging to sexual minorities is the subject of careful study of many sociologists, psychologists and representatives of other social and humanitarian sciences. 
This is a substrate criterion for describing stigmatization. B. G. Everett, M.L.Hatzenbuehler and T.L.Hughes [7] set the objective to determine whether legislative initiatives (such as, for example, the legalization of civil marriage) affect the consciousness and health of sexual minorities (especially women). The authors consider the link between some social and demographic characteristics (race, ethnicity, education) and the processes of social and psychological discrimination of these groups, The authors also argue that the social policy supporting the civil rights of sexual minorities (especially women) improves their psychological state, contributes to the formation of a more responsible attitude towards their health. They also note that the most powerful effect of such a policy is observed among women of color.

Studying interpersonal interactions involving people with a stigmatized identity (eg, sexual minorities, mental disability, etc.), A.-K. Newheiser, M. Barreto [8] note that individuals tend to hide their stigmatized identity from partners to avoid unnecessary bias on their part. Scientists have put forward a rather bold hypothesis: the concealment of one's stigmatized identity can help to reduce their personal dependence on this stigma, as well as to lead to a decrease in emotional dependence on it. And with the further development of interpersonal interactions (partner communications) this effect only increases.

The problem of social and psychological discrimination of transgender people is actively studied by modern researchers. Thus, C. N.Thoroughgood, K. B.Sawyer and J. R. Webster [9] refer to cognitive processes forming paranoid perception of this contingent of people (transgenders) by ordinary people in the process of fulfilling their professional work responsibilities. Scientists come to the conclusion that excessive suspicion of people to "transgender colleagues" is due to emotional exhaustion accumulated during their work duties. From this point of view, a paranoid and suspicious attitude provokes organizational transgender discrimination and complicates intra-group professional cooperation.

Continuing to discuss the problems of transgender discrimination, J. M. White Hughto, S. L. Reisner and J. E. Pachankis [10] argue that this stigma acts on several levels: individual, interpersonal, and social structural. Each of these levels has its specific causal relationships between social conditions of the development of stigma itself, medical parameters of a stigmatized transgender person, and the intensity of group interactions in the communities of the transgender people themselves. The authors note that in order to prevent negative consequences of "transgender stigma", we need an integrated approach which takes into account various determinants. In a certain sense, this position falls under historical criterion of analyzing the problem of stigmatization. The authors give an overview of determinants of origin and mechanisms for "transgender stigma" implementation.

J. E. Baur, A. V. Hall, S. R. Daniels, M. R. Buckley and H. J. Anderson [11] pay attention to a truly pressing social issue: the resocialization of the so-called ex-offenders. These individuals convicted for their crimes have served their sentences and are trying to undergo a spontaneous social rehabilitation. They also play a specific and not always constructive social role in everyday social processes. Using an interdisciplinary approach, the authors point out that the following lines are intertwined in the process of stigmatization: general stereotypical portrayal of ex-offenders by ordinary population (usually negative value characterization), production and economic potential of this type of workers (which in turn affects labor productivity), civil initiatives of a society aimed at providing substantive assistance to exoffenders in the process of their re-socialization. The authors propose to develop effective strategies that former criminals could use their own negative social experience to overcome.

Such basis of stigmatization as the established stereotypes of a "successful person" is particularly interesting. (Research in this area demonstrates belonging to the functional criterion of stigmatization study.) It should be noted that, in this regard, the most vulnerable are men for whom socially significant assessments of their status are the most important factors in their life strategy. C. J. Taylor [12] notes that the risk of being labeled as the "failed man" mostly affects individuals who lost their social influence in a male environment for various reasons. The consequences can be psychological stress or even a physiological body imbalance. As an objective indicator of resistance to stress, the author suggests using medical data on the level of cortisol in the body of observed patients. Increasing of the level of cortisol in the body is a kind of physiological response of the individuals who are not able to build influence in a team. This emphasizes the importance of acquiring and maintaining the status of a "real man" by maintaining the social influence on other participants in group interaction.

In the context of studying stigmatization processes, the researchers pay particular attention to the so-called territorial stigmatization. The place of residence often determines the quality and level of human life.

L. Wacquant, T. Slater and V.B. Pereira [13] show a dynamic interaction of various components of social environment: territorial administrative units, cultural symbolic group behavior models and everyday individual actions. Using numerous examples of European (e.g. Paris, Stockholm, Bristol, Edinburgh, Copenhagen) and American (e.g. New York, Chicago) urban areas, authors reveal close connection of three spatial structures in a single urban ontology: symbolic space, social space and physical space. The authors argue that the processes of modern territorial stigmatization have following characteristics: 1. Close relationship with the ethnicity of the participants in this process; 2 . Phenomenon of territorial stigmatization is viewed by society as a matter of course, as a kind of visible attribute of the "social hell"; 3 . Stigmatized areas of modern post-industrial cities embody the vectors of social disintegration (general promiscuity); 4. Hypertrophy of racial or religious characteristics of the inhabitants of these territories provokes the intensification of stigmatization processes; 5 . Stigmatized areas of a modern city cause negative reactions (emotions, opinions, assessments) of residents of the so-called normal areas, which in turn facilitates the philistine justification of tough measures by the government (restrictions on rights, fines, punishments). Moreover, public services manipulate this image of disadvantageous areas in public opinion in order to promote their strategies in territories development (for example, the demolition of entire neighborhoods or the radical reconstruction of urban areas). This is an obvious direct social and political manipulation of this problem instead of a 
thorough investigation of the causes, conditions and factors of its current reproduction, as well as the development of methods of its promising overcoming on such basis. The authors result their study with the thesis that, as an anchor of social discredit, the territorial stigmatization plays a key role in the substantive and symbolic cultural transformation of a modern urban landscape. It should be emphasized that this study most clearly reflects the substrate criterion for the stigmatization analysis.

Considering the peculiarities of urban marginal areas development, S. Q. Jensen and A.-D. Christensen [14] have noticed that the residents of these territories accept their marginal status as a matter of course, without any critical reflection. Moreover, such uncritical self-determination only strengthens the effect of territorial stigmatization. Residents of marginal territories are used to their stigmatized position, and are even subjectively happy with their status. The authors believe that state institutions and the development of political culture of the whole society should play a certain role in overcoming this negative effect.

S. Antonia and L. de Wetering [15] analyze the process of stigmatization by assassing the life of young people in the suburbs of Paris (Bondi). They emphasize that the basis for constructing the stigmatized personality of a young person is the internalization of attributive identity. However, the process of transformation of external social norms and forms of communication into stable internal qualities of the personality itself is often indirect. One way of such indirect socialization is externalization acting as a mechanism for protecting one's own personal identity. In other words, from the authors' point of view, young people objectively differentiated according to the territorial and administrative basis (place of residence) subjectively exclude the discourse of stigmatization and deviance from their own self-identification. The authors believe that we should abandon simplified approaches in describing this contingent of young people, and treat these groups of population more as "living together in diversity" and capable of sufficient dynamic development in the social structures.

In turn, in analyzing the experience of stigmatization process research, the system and criteria approach presented above makes it possible to emphasize a certain ambivalence of the forms of the social identity process itself. The essence of ambivalence is most clearly manifested in the discrepancy between real and the so-called virtual identity. In this case, a person is in a situation of direct or indirect contradiction between inner experience of their belonging to the relevant social group, on the one hand, and the evaluation of their place and role by other representatives of this group, on the other.

Virtual social identity is an imaginary image that some participants of social interaction form in relation to other participants. Real social identity has a basis in objectified human attributes, such as skin color, race, gender, nationality. Any individual who has a certain gap between these identities is "labeled" (stigmatized) or subjected to discrimination. Stigma is not a substrate or an objective difference; it has a value origin reflecting traditional differences in a society between "normal" and "abnormal".

In other words, the process of stigmatization serves only as a mean of overcoming specific ambivalence of social values of various social agents and participants of social interactions.
In attempts to explain the mechanism of stigmatization processes, supporters of symbolic interactionism do not analyze the essence of these processes and their impact on socialization and social identity of an individual. This sociological concept, in fact, is only a practical sociological tool, without claiming to identify certain patterns, trends, or generalizing empirical material.

\section{CONCLUSION}

In its essence, deviation is an indispensable factor in the interaction of social groups competing with each other in nomination, substantiation and justification of certain social values. Competitiveness of social environment is the basis which constantly provokes the phenomenon of deviation.

Deviation serves as a necessary social building which inevitably ensures the unity and stability of a society. It is the exclusion of deviants from the range of socially justified circumstances and conditions of existence that gives the legal majority of a society the right to justify their own norms, and demonstrates the significance of the established rules.

Stigmatization is a necessary condition, and, at the same time, the result of a social identity process characterized by certain ambivalence, which is clearly expressed in the discrepancy between real and virtual identity.

Stigma is not a substrate or objective difference between people. Rather, it has a value origin reflecting traditional differences in a society between "normal" and "abnormal". Stigma is a mean of overcoming existing ambivalence of social values of various social agents and participants of social interactions.

\section{REFERENCES}

[1] C. Sikorski, M. Luppa, M. C. Angermeyer, G. Schomerus, B. Link, and S. G. Riedel-Heller, "The association of BMI and social distance towards obese individuals is mediated by sympathy and understanding," Social Science \& Medicine, vol. 128, pp. 25-30, March 2015.

[2] S. J. Mooney, and A. M. El-Sayed, "Stigma and the etiology of depression among the obese: An agent-based exploration," Social Science \& Medicine, vol. 148, pp. 1-7, January 2016.

[3] N. Tuntiya, "The "Dignity of the Sick": Managing Social Stigma by Mental Patients in the Community", in Brea L. Perry (ed.) 50 Years After Deinstitutionalization: Mental Illness in Contemporary Communities (Advances in Medical Sociology, vol. 17) Emerald Group Publishing Limited, pp. $235-260$.

[4] T. Moses, "Determinants of mental illness stigma for adolescents discharged from psychiatric hospitalization," Social Science \& Medicine, vol. 109, pp. 26-34, May 2014.

[5] M. Kayama, and W. Haight, "Balancing the stigmatization risks of disability labels against the benefits of special education: Japanese parents' perceptions," Children and Youth Services Review, vol.89, pp. 43-53, June 2018.

[6] H. J. Whittle, K. Palar, N. A. Ranadive, J. M. Turan, M. Kushel, and S. D. Weiser, "The land of the sick and the land of the healthy: Disability, bureaucracy, and stigma among people living with poverty and chronic illness in the United States," Social Science \& Medicine, vol. 190, pp. 181-189, October 2017

[7] B. G. Everett, M. L. Hatzenbuehler, and T. L. Hughes, "The impact of civil union legislation on minority stress, depression, and hazardous drinking in a diverse sample of sexual-minority women: A quasi-natural experiment," Social Science \& Medicine, vol. 169, pp. 180-190, November 2016

[8] A.-K. Newheiser, and M. Barreto "Hidden costs of hiding stigma: Ironic interpersonal consequences of concealing a stigmatized identity in social interactions," Journal of Experimental Social Psychology, vol. 52, pp. 58-70, May 2014. 
[9] C. N. Thoroughgood, K. B. Sawyer, and J. R. Webster, "What lies beneath: How paranoid cognition explains the relations between transgender employees' perceptions of discrimination at work and their job attitudes and wellbeing," Journal of Vocational Behavior, vol. 103, Part A, pp. 99-112, December 2017.

[10] J. M. White Hughto, S. L. Reisner, and J. E. Pachankis, "Transgender stigma and health: A critical review of stigma determinants, mechanisms, and interventions," Social Science \& Medicine, vol. 147, pp. 222-231, December 2015.

[11] J. E. Baur, A. V. Hall, S. R. Daniels, M. R. Buckley, and H. J. Anderson, "Beyond banning the box: A conceptual model of the stigmatization of ex-offenders in the workplace," Human Resource Management Review, vol. 28, iss. 2, pp. 204-219, June 2018.
[12] C. J. Taylor, "Physiological stress response to loss of social influence and threats to masculinity," Social Science \& Medicine, vol. 103, pp. 51-59, February 2014.

[13] L. Wacquant, T. Slater, and V. B. Pereira, "Territorial Stigmatization in Action," Environment and Planning A, vol. 46, iss.6, pp. 1270 - 1280, January 2014.

[14] S. Q. Jensen, and A.-D. Christensen "Territorial stigmatization and local belonging," City, vol. 16, pp. 74-92, 2012.

[15] S. Antonia, and L. Wetering "Stigmatization and the social construction of a normal identity in the Parisian banlieues," Geoforum, June 2017, in press. 